\section{OPEN ACCESS}

Approved by:

Frontiers Editorial Office,

Frontiers Media SA

Switzerland

*Correspondence: Dai-Jin Kim

kdj922@catholic.ac.kr In Young Choi

iychoi@catholic.ac.kr

Specialty section: This article was submitted to

Addictive Disorders,

a section of the journal

Frontiers in Psychiatry

Received: 25 March 2019 Accepted: 04 April 2019 Published: 26 April 2019

Citation: Lee S-J, Choi MJ, Rho MJ, Kim D-J and Choi IY (2019)

Corrigendum: Factors Affecting

User Acceptance in Overuse of Smartphones in Mobile

Health Services: An Empirical

Study Testing a Modified Integrated Model in South Korea.

Front. Psychiatry 10:259.

doi: 10.3389/fpsyt.2019.00259

\title{
Corrigendum: Factors Affecting User Acceptance in Overuse of Smartphones in Mobile Health Services: An Empirical Study Testing a Modified Integrated Model in South Korea
}

\begin{abstract}
Seo-Joon Lee ${ }^{1}$, Mun Joo Choi ${ }^{2,3}$, Mi Jung Rho ${ }^{2,4}$, Dai-Jin Kim ${ }^{5,6 *}$ and In Young Choi ${ }^{2,3,4 *}$
${ }^{1}$ Research Institute of Health Science, Korea University, Seoul, South Korea, ${ }^{2}$ Department of Medical Informatics, The Catholic University of Seoul, Seoul, South Korea, ${ }^{3}$ Department of Biomedicine and Health Sciences, College of Medicine, The Catholic University of Korea, Seoul, South Korea, ${ }^{4}$ Catholic Institute for Healthcare Management and Graduate School of Healthcare Management and Policy, The Catholic University of Korea, Seoul, South Korea, ${ }^{5}$ Department of Psychiatry, Addiction Research Institute, Seoul St. Mary's Hospital, College of Medicine, The Catholic University of Korea, Seoul, South Korea, ${ }^{6}$ Department of Psychiatry, Seoul St. Mary's Hospital, College of Medicine, The Catholic University of Korea, Seoul, South Korea
\end{abstract}

Keywords: smartphone overuse, m-Health, TAM, UTAUT, acceptance

\section{A corrigendum on}

Factors Affecting User Acceptance in Overuse of Smartphones in Mobile Health Services: An Empirical Study Testing a Modified Integrated Model in South Korea

by Lee S-J, Choi MJ, Rho MJ, Kim D-J and Choi IY (2018) Front. Psychiatry. 9:658. doi: 10.3389/ fpsyt.2018.00658

In the original article, we neglected to include the funder "Brain Research Program through the National Research Foundation of Korea (NRF) founded by the Ministry of Science, ICT \& Future Planning, NRF-2015M3C7A1064796" to all authors.

A correction has therefore been made to the Acknowledgements:

"This research was supported by the Brain Research Program through the National Research Foundation of Korea (NRF) founded by the Ministry of Science, ICT \& Future Planning, NRF2014M3C7A1062893 and NRF-2015M3C7A1064796."

The authors apologize for this error and state that this does not change the scientific conclusions of the article in any way. The original article has been updated.

Copyright (c) 2019 Lee, Choi, Rho, Kim and Choi. This is an open-access article distributed under the terms of the Creative Commons Attribution License (CC BY). The use, distribution or reproduction in other forums is permitted, provided the original author(s) and the copyright owner(s) are credited and that the original publication in this journal is cited, in accordance with accepted academic practice. No use, distribution or reproduction is permitted which does not comply with these terms. 